\title{
Hidrolisis Pati dari Batang Kelapa Sawit dengan Kombinasi Perlakuan Asam Sitrat dan Steam Explosion Terhadap Sifat Fisiko Kimia Dekstrin
}

\author{
Hydrolysis of Oil Palm Stem Starch by Combination Between Citric Acid and Steam Explosion on \\ Physicochemical Properties of Dextrin
}

Syarifah Yusra1,2, Yudi Pranoto², Chairil Anwar³, Chusnul Hidayat²*

1Departemen Agroteknologi, Fakultas Pertanian, Universitas Sains Cut Nyak Dhien, Nangro Aceh Darussalam

2Departemen Teknologi Pangan dan Hasil Pertanian, Fakultas Teknologi Pertanian, Universitas Gadjah Mada, Yogyakarta

3Jurusan Kimia, Fakultas Matematika dan IImu Pengetahuan Alam, Universitas Gadjah Mada, Yogyakarta

*Korespondensi dengan penulis (chusnul@gadjahmada.edu)

Artikel ini dikirim pada tanggal 07 November 2019 dan dinyatakan diterima tanggal 03 Februari 2020. Artikel ini juga dipublikasi secara online melalui https://ejournal2.undip.ac.id/index.php/jatp. Hak cipta dilindungi undang-undang. Dilarang diperbanyak untuk tujuan komersial.

Diproduksi oleh Indonesian Food Technologists® @2020

\begin{abstract}
Abstrak
Modifikasi pati dilakukan untuk memperbaiki sifat fungsional pati dan memperluas penggunaan pati dalam produk pangan. Modifikasi pati menjadi dekstrin dapat dilakukan baik secara fisik, kimiawi, atau kombinasi fisikokimia. Pada penelitian ini dilakukan modifikasi pati dengan kombinasi pregelatinisasi-steam explosion (Pregel-SE), dan kombinasi pregelatinisasi-asam sitrat-steam explosion pada pH 4 (pregel-pH4-SE) dan pH 3 (pregel-pH3-SE) untuk produksi dekstrin. Tujuan dari penelitian ini adalah untuk memperoleh metode hidrolisis terbaik dalam pembuatan dekstrin. Produk yang dihasilkan diamati tingkat kelarutan, berat molekul (Mw), dextrose equivalent (DE), Spectra Fourier Transform Infrared (FTIR), SEM, dan viskositas pasta. Hasil menunjukkan bahwa kondisi terbaik modifikasi pati menjadi dekstrin diperoleh pada perlakuan pregel-pH3-SE. Pada perlakuan ini diperoleh kelarutan $75,94 \%$, berat molekul $60100 \mathrm{~g} / \mathrm{mol}$ dan DE 15,92\%. Pita vibrasi baru terlihat di wilayah bilangan gelombang 1717 $\mathrm{cm}^{-1}$ pada analisis FTIR. Hasil SEM menunjukkan bahwa bentuk granula pati yang bulat sudah tidak terlihat setelah kombinasi perlakuan. Pengujian RVA menunjukkan penurunan viskositas berkorelasi positif terhadap penurunan berat molekul, peningkatan kelarutan dan DE setelah kombinasi perlakuan ditingkatkan. Metode kombinasi steam explosion dan asam sitrat (pregel-pH-SE) efektif menghidrolis pati batang kelapa sawit menjadi dekstrin sehingga mampu memperbaiki sifat fisiko kimianya.
\end{abstract}

Kata kunci: hidrolisis asam, modifikasi pati, pati batang kelapa sawit, pregelatinisasi, steam explosion.

\begin{abstract}
Starch modification is performed to improve the functional properties of starch and starch utilization in food products. Modification of starch, such as dextrin, can be performed by physical and chemical methods, or a combination method, such as physico-chemical. In this research, starch modification was carried out by a combination between pregelatinization and steam explosion (Pregel-SE), a combination between pregelatinization, citric acid and steam explosion at pH 4 (Pregel-pH-SE4) and at pH 3 (Pregel-pH-SE3) for the production of dextrin. The objective of this research was to obtain the best method for dextrin production. Levels of solubility, molecular weight $(M w)$, dextrose equivalent (DE), Spectra Fourier Transform Infrared (FTIR), SEM, and pasting properties (RVA) were observed. The results showed that the best condition of starch modification for dextrin production was obtained by Pregel-pH3-SE. Solubility, molecular weight, and DE of dextrin were $75.94 \%, 60100 \mathrm{~g} / \mathrm{mol}$, and $15.92 \%$, respectively. A new peak was observed in the region of the wavenumber $1.717 \mathrm{~cm}^{-1}$ at FTIR analysis. SEM analysis indicated that the round form of starch granules did not observed after the treatments. RVA analysis showed that the decrease in viscosity was correlated with a decrease in molecular weight, an increase in solubility, and DE after the treatments. As conclusion, a combination method between steam explotion and citric acid (pregel-pH-SE) is useful for the hydrolysis process of oil palm stem starch to dextrin so it might improve its physicochemical properties
\end{abstract}

Keyword: Acid hydrolysis, modified starch, oil palm stem starch, pregelatinization, steam explosion.

\section{Pendahuluan}

Batang kelapa sawit mengandung pati cukup tinggi sehingga sangat potensial sebagai sumber karbohidrat yang dapat digunakan baik dalam bidang pangan dan non pangan (Ridwansyah et al., 2010; Azemi, et al., 1999). Pati secara umum adalah bahan utama yang dihasilkan oleh tumbuhan untuk menyimpan glukosa (sebagai produk fotosintesis) dalam jangka panjang (More et al., 2017). Kandungan amilosa, amilopektin dan struktur granula pati berbeda-beda dan tergantung dari sumber pati. Hal ini menyebabkan perbedaan sifat fungsional pati (Khan et al., 2019). Oleh karena itu, modifikasi pati sering dilakukan untuk memperbaiki sifat pati, antara lain sifat fisiko-kimia pada pati ubi jalar (Trung et al., 2017; Babu et al., 2015), pati garut (Astuti et al., 2018), atau sebagai resistant starch (Khan et al., 2019; Faridah et al., 2013) dan dekstrin (Majumdar et al. 2015). Modifikasi pati batang kelapa 
sawit juga dilakukan untuk bahan baku bioplastik (Cahyaningtyas et al., 2019). Modifikasi pati bertujuan untuk mengubah atau memperbaiki sifat pati sehingga menghasilkan sifat yang lebih baik atau memperoleh produk turunan pati. Industri pengguna pati menginginkan pati yang mempunyai kelarutan yang tinggi, dan viskositas yang stabil pada kondisi asam dan suhu tinggi, serta tahan terhadap perlakuan mekanis (Trung et al., 2017).

Modifikasi pati dapat dilakukan secara enzimatis (Wong et al., 2007; Shang et al., 2018; Munegumi et al., 2016; Liu, 2002; Blazek and Gilbert, 2010; Rahmawati dan Sutrisno, 2015; Wanderley et al., 2013; Sarifudin and Assiry, 2013) dan kimiawi (Utrilla-Coello et al., 2014; Ferrinia et al., 2008, Dutta et al., 2011; Mei et al., 2015; Olivato et al., 2012; Dastidara and Netravali, 2012). Salah satu proses untuk memodifikasi pati adalah hidrolisis. Hidrolisis secara enzimatis memotong ikatan glikosidik secara spesifik sehingga dihasilkan produk yang lebih spesifik (Majumdar et al., 2015, Triyono et al., 2017; Permanasari dan Yulistiani, 2017). Namun kelemahannya adalah waktu reaksi yang lebih lama dan harga enzim mahal, sedangkan kelebihan dari hidrolisis secara kimiawi adalah waktu reaksi lebih cepat (UtrillaCoello et al., 2014; Dutta et al., 2011). Namun kelemahannya adalah asam kuat $\left(\mathrm{H}_{2} \mathrm{SO}_{4}\right.$, sodium thiosulfat dan $\mathrm{HCl}$ ) sangat korosif sedangkan asam lemah (asam sitrat) menghasilkan dextore equivalent rendah (Mei et al., 2015; Babu et al., 2015; Olsson et al., 2013). Selain itu, katalis asam kuat mengakibatkan terbentuknya produk samping antara lain hasil reaksi maillard sehingga produk berwarna coklat kehitaman. Oleh karena itu, perlu dicari metode yang tepat untuk hidrolisis pati menggunakan asam lemah yang dikombinasi dengan proses lainnya.

Akhir-akhir ini, steam explosion (SE) menjadi perhatian banyak peneliti untuk menghidrolisis selulosa dari tanaman (Aktas-Akyildiz et al., 2017; Bi et al., 2017; Adapa et al., 2010; Sui et al., 2018; Jacquet et al., 2012). Prinsip dasar dari SE adalah material terpapar uap jenuh bertekanan tinggi untuk jangka waktu tertentu, kemudian diikuti dengan melepaskan tekanan secara tiba-tiba. Perlakuan SE digunakan untuk merusak struktur kristal selulosa dan membuat hemiselulosa lebih mudah diakses untuk proses berikutnya (Bi et al., 2017). Efek perubahan tekanan yang tiba-tiba dalam reaktor menyerupai ledakan yang menyebabkan bahan mengalami dekomposisi struktur.

Selain itu, pati dalam suspensi pati cenderung mengendap. Hal ini menjadi kendala saat proses SE karena proses gelatinisasi tidak merata pada saat pemanasan sehingga tidak semua pati dapat larut. Beberapa peneliti melakukan perlakuan pendahuluan pregelatinisasi untuk meningkatkan kelarutan pati sebelum modifikasi pati secara kimia atau fisik (Gbenga et al., 2014; Waliszewskia et al., 2003; Khanna and Tester, 2006).

Selulosa tanaman lebih tahan terhadap hidrolisis dibandingkan dengan pati. Namun aplikasi SE pada pati belum banyak dilakukan. Disamping itu, penggunakan katalis asam kuat dapat menyebabkan produk samping yang tidak diinginkan dan korosif, sedangkan penggunaan asam lemah saja menghasilkan DE rendah. Oleh karena itu, pada penelitian ini dilakukan hidrolisis pati menggunakan kombinasi teknik SE dengan asam lemah yaitu asam sitrat. Tujuan dari penelitian ini adalah memperoleh dektrin dari pati batang kelapa sawit melalui proses kombinasi pregelatinisasi, hidrolisis asam dan steam explosion. Produk dievaluasi antara lain struktur, tingkat kelarutan, berat molekul, dextrose equivalent (DE), Spectra Fourier Transform Infrared (FTIR), Scanning Electron Microscopy (SEM), dan viskositas pasta.

\section{Material dan Metode \\ Material}

Bahan baku adalah batang kelapa sawit yang berumur \pm 25 tahun (tidak produktif) berasal dari peremajaan Institut Penelitian Perkebunan Yogyakarta (LPP), Jawa Tengah, Indonesia. Larutan etanol 95\%, $\mathrm{K}_{2} \mathrm{SO}_{4}, \mathrm{HgO}, \mathrm{H}_{2} \mathrm{SO}_{4}, \mathrm{NaOH}$, asam sitrat, reagen DNS, $\mathrm{H}_{2} \mathrm{SO}_{4} 95-97 \%$, KI, sodium hypochlorite, potassium hydroxide, reagen folin-ciocalteu (Merk, Germany). Somoygi reagent, larutan lugol, iod, $\mathrm{HCl} 37 \%$, Glukosa (Sigma-Aldrich, Germany). Bahan kimia yang digunakan mempunyai derajat pro analysis. Peralatan yang digunakan terdiri dari timbangan analitik (Shimadzu, Japan), centrifuge (Centrifuge Damon/IEC Division, USA), oven (Memmert, Germany), spektrofotometer Genesys 20 (Thermo, USA), vortex (Velp Scientifica, Italy), Rapid Visco Analysis RVA 4500 (Perten Instruments, Sweden), FTIR Thermo Nicolet i50 spectrometer (Waltham, USA), SEM atau Scanning Electron Nicroscope JSM- 5320LV (Jeol, US), stirrer (Labinco, Netherland), blender (Philips, Germany), cabinet dryer, steam explosion, dan peralatan gelas.

\section{Prosedur Ekstraksi Pati}

Ekstraksi pati kelapa sawit dilakukan berdasarkan Ridwansyah et al. (2010). Batang kelapa sawit yang sudah ditebang, diambil bagian atas ( 2 meter bagian pucuk). Kulit luar batang dibuang untuk diambil bagian empelurnya. Selanjutnya empelur diparut sehingga diperoleh serbuk kayu. Ekstraksi pati dari serbuk kayu dilakukan secara basah dengan rasio serbuk kayu dan air 1 : 3. Selanjutnya ampas dipisahkan. Suspensi pati diendapkan selama 3 jam. Pati yang diperoleh di keringkan didalam oven pada suhu $105^{\circ} \mathrm{C}$ selama 24 jam. Pengecilan ukuran gumpalan pati kering dilakukan menggunakan ayakan 60 mesh.

\section{Modifikasi Hidrolisis Pati}

Modifikasi pati batang kelapa sawit dilakukan sesuai dengan metode Olsson et al. (2013) dengan modifikasi. Sebanyak $10 \mathrm{~g}$ pati dicampur dengan aquades hingga mencapai volume $100 \mathrm{ml}$. Suspensi diaduk dan dipanaskan dalam reaktor steam explosion sampai mencapai suhu pregelatinisasi $\left(70-80^{\circ} \mathrm{C}\right)$. Setelah mencapai suhu pregelatinisasi, reaktor ditutup dan dipanaskan sampai suhu $120^{\circ} \mathrm{C}$. Selanjutnya katup reaktor dibuka secara tiba-tiba sehingga timbul ledakan (modifikasi pregel-SE). Modifikasi Pregel-pH-SE 
dilakukan dengan menambahkan larutan asam sitrat 0,1 $\mathrm{M}$ ke dalam suspensi pati sampai $\mathrm{pH}$ mencapai 3 dan 4 pada volume $100 \mathrm{ml}$. Proses selanjutnya sesuai dengan modifikasi pregel-SE. Sampel dari SE dikeringkan dalam cabinet dryer pada suhu $50-60^{\circ} \mathrm{C}$ selama 24 jam. Sampel yang telah kering dihaluskan dan diayak menggunakan ayakan 80 mesh sehingga diperoleh bubuk dekstrin dengan ukuran yang seragam. Selanjutnya bubuk dekstrin dikarakterisasi.

\section{Analisis kadar air}

Analisis kadar air mengacu pada AOAC (1971). Sebanyak $1 \mathrm{~g}$ sampel dekstrin dimasukkan dalam botol timbang yang telah diketahui beratnya. Sampel dipanaskan dalam oven pada suhu $105^{\circ} \mathrm{C}$ sampai didapat berat tetap. Kadar air sampel dihitung didasarkan pada perbedaan berat sampel sebelum dan sesudah dikeringkan.

\section{Analisis Kadar Abu}

Sebanyak 2,0-3,0 g sampel dekstrin ditimbang di dalam cawan porselen (kurs) yang telah diketahui berat konstan, dan kurs yang sudah diisi sampel tersebut dibakar hingga tidak berasap lagi (AOAC, 1971). Selanjutnya kurs tersebut dimasukkan dalam tanur listrik bersuhu $600^{\circ} \mathrm{C}$ sampai pengabuan sempurna. Setelah pengabuan selesai, cawan contoh didinginkan dalam desikator, kemudian ditimbang. Penimbangan diulangi kembali hingga diperoleh bobot tetap. Kadar abu sampel ditentukan dengan menimbang sisa mineral hasil pembakaran bahan organik.

\section{Analisis Kelarutan}

Uji kelarutan dilakukan dengan metode Trung et al. (2017) dengan modifikasi. Sebanyak 0,5 g sampel dilarutkan dalam $50 \mathrm{ml}$ aquades (konsentrasi 1\%). Selanjutnya dilakukan pengadukan dengan homogenizer T50 basic (IKA, Germany) pada 4000 rpm selama 2 menit. Suspensi disentrifugasi selama 20 menit. Kemudian $25 \mathrm{ml}$ supernatant dimasukkan ke dalam botol vial. Selanjutnya dikeringkan sampai berat konstan didalam oven pada suhu $105^{\circ} \mathrm{C}$. Persentase kelarutan dinyatakan sebagai persentase bobot sampel kering terhadap bobot sampel awal.

\section{Scaning Electron Microscopy}

Sampel serbuk dekstrin diamati dengan SEM-EDS. Sampel ditempatkan diatas stubs lalu dilapisi emas menggunakan alat gold sputter coater selama 10 menit. Sampel yang telah dilapisi ditempatkan ke dalam mikroskop SEM lalu diamati sampai perbesaran hingga $1000 \times$ (Babu et al., 2015).

\section{Spectra Fourier Transform Infrared}

Spectra Fourier Transform Infrared (FTIR) pada sampel ditentukan dengan spectrometer. Sampel bubuk dicampur dengan $\mathrm{KBr}$ dan diletakkan ke dalam pelet. Spektra FTIR didapatkan dengan peneraan pada panjang gelombang 400 hingga $4000 \mathrm{~cm}^{-1}$.

\section{Analisis Sifat Pasting}

Sifat pasting pati batang pelepah dan batang keras kelapa sawit diukur menggunakan Rapid Visco Analyzer (RVA). Sebanyak $3 \mathrm{~g}$ sampel ditimbang dalam wadah RVA, lalu ditambahkan $25 \mathrm{~g}$ aquades. Pengukuran dengan RVA mencakup fase proses pemanasan dan pendinginan pada pengadukan konstan (160 rpm), suspensi pati dipanaskan dari suhu 50 hingga $95^{\circ} \mathrm{C}$ dengan kecepatan $6^{\circ} \mathrm{C} /$ menit, lalu dipertahankan pada suhu tersebut (holding) selama 5 menit. Setelah fase pemanasan selesai, pasta pati didinginkan dari suhu $95^{\circ} \mathrm{C}$ menjadi suhu $50^{\circ} \mathrm{C}$ dengan kecepatan $6^{\circ} \mathrm{C} /$ menit, kemudian suhu dipertahankan pada suhu $50^{\circ} \mathrm{C}$ selama 2 menit. Hubungan antara viskositas ( $\mathrm{cP}$ ) sebagai fungsi dari suhu $\left({ }^{\circ} \mathrm{C}\right)$ selama fase pemanasan dan pendinginan dievaluasi untuk mengetahui profil gelatinisasi.

\section{Prosedur Analisis Dextrose Equivalent}

Penentuan DE didasarkan pada jumlah ikatan glikosida yang berhasil dihidrolisis yang dinayatakan sebagai jumlah gula reduksi. Nilai gula reduksi diukur dengan menggunakan metode dinitrosalicylic acid (Miller, 1959). DE dihitung sebagai rasio persentase gula pereduksi (g) dan sampel kering $(\mathrm{g})$.

\section{Prosedur Perhitungan Berat Molekul}

Bobot berat molekul $\left(\mathrm{M}_{\mathrm{w}}\right)$ diperoleh dari pengukuran dengan menggunakan viskometer Oswald. Berat molekul dihitung berdasarkan persamaan MarkHouwink, dimana harga dari $\mathrm{k}$ dan $\alpha$ untuk Dekstrin adalah 2,43 x 10-3 dan 0,337 (Avaltroni et al., 2004).

\section{Analisis statistik}

Hasil analisis kadar air, kadar abu dan kelarutan produk dianalisis secara statistik menggunakan ANOVA. Apabila terdapat perbedaan nyata (significant) maka analisis dilanjutkan dengan uji Duncan Multiple range Test pada taraf uji 5\%.

\section{Hasil dan Pembahasan}

\section{Analisis Kadar air}

Tabel 1 menunjukkan kadar air pada perlakuan SE tanpa asam sitrat (Pregel-SE) berbeda nyata dengan perlakuan pregel-pH3-SE dan pregel-pH4-SE. Kadar air dekstrin menurun sebesar 1,2 kali pada kombinasi perlakuan dengan penambahan asam sitrat. Perbedaan kadar air dapat dipengaruhi oleh proses pengeringan. Selain itu, penurunan kadar air dapat disebabkan oleh degradasi molekul pati pada proses SE dan asam. Degradasi molekul pati menjadi lebih intensif pada penambahan asam citrat (Babu et al., 2015) dan mengakibatkan berat molekul dekstrin semakin lebih kecil. Hal ini dapat menurunkan interaksi antara molekul dekstrin dan air sehingga kadar air dekstrin turun.

\section{Analisis Kadar Abu}

Abu sampel adalah bahan an-organik non-volatil dari suatu senyawa yang tidak menguap setelah dilakukan pemanasan pada suhu tinggi. Oleh karena itu, kadar abu dapat mengindikasikan residu bahan setelah 
Tabel 1. Karakteristik sifat fisiko-kimia dekstrin kombinasi modifikasi asam sitrat dan steam explosion pati batang kelapa sawit

\begin{tabular}{lccc}
\hline Sampel & Kadar Air (\%) & Kadar Abu (\%) & Kelarutan (\%) \\
\hline Pregel-SE & $9,39 \pm 0,04^{\mathrm{a}}$ & $0,51 \pm 0,11^{\mathrm{a}}$ & $60,08 \pm 0,34^{\mathrm{a}}$ \\
Pregel-pH4-SE & $8,80 \pm 0,13^{\mathrm{b}}$ & $0,63 \pm 0,02^{\mathrm{b}}$ & $64,4 \pm 0,98^{\mathrm{b}}$ \\
Pregel-pH3-SE & $7,82 \pm 0,67^{\mathrm{c}}$ & $0,61 \pm 0,07^{\mathrm{b}}$ & $75,94 \pm 0,6^{\mathrm{c}}$ \\
\hline
\end{tabular}

Keterangan: angka yang diikuti huruf yang berbeda pada kolom yang sama menunjukkan adanya perbedaan yang nyata $(p>0,05)$

Tabel 2. Nilai dextrose equivalent dan berat molekul dekstrin kombinasi modifikasi asam sitrat dan steam explosion pati kelapa sawit

\begin{tabular}{lcc}
\hline Sampel & $\begin{array}{c}\text { Dextrose Equivalent } \\
(\%)\end{array}$ & $\begin{array}{c}\text { Berat Molekul } \\
(\mathrm{g} / \mathrm{mol})\end{array}$ \\
\hline Pregel-SE & $11,16 \pm 0,46^{\mathrm{c}}$ & 925.000 \\
Pregel-pH4-SE & $12,43 \pm 0,51^{\mathrm{b}}$ & 80.400 \\
Pregel-pH3-SE & $15,92 \pm 0,68^{\mathrm{a}}$ & 60.100
\end{tabular}

Keterangan: angka yang diikuti huruf yang berbeda pada kolom yang sama menunjukkan adanya perbedaan yang nyata $(p>0,05)$

Tabel 3. Profil pasta dekstrin pati batang kelapa sawit

\begin{tabular}{lcccccc}
\hline Perlakuan & SAG ${ }^{\circ}(\mathrm{C})$ & PV $(\mathrm{cP})$ & TV $(\mathrm{cP})$ & BV $(\mathrm{cP})$ & FV $(\mathrm{cP})$ & SV $(\mathrm{cP})$ \\
\hline Pregel-SE & $\mathrm{tt}$ & $52,3 \pm 2,89^{\mathrm{a}}$ & $50,7 \pm 1,90^{\mathrm{a}}$ & $4,0 \pm 1,0^{\mathrm{a}}$ & $80,3 \pm 1,5^{\mathrm{a}}$ & $29,67 \pm 1,04^{\mathrm{a}}$ \\
Pregel-pH4-SE & $\mathrm{tt}$ & $22,0 \pm 1,00^{\mathrm{b}}$ & $16,3 \pm 3,80^{\mathrm{b}}$ & $3,3 \pm 0,6^{\mathrm{a}}$ & $23,7 \pm 1,8^{\mathrm{b}}$ & $7,33 \pm 2,08^{\mathrm{b}}$ \\
Pregel-pH3-SE & $\mathrm{tt}$ & $18,0 \pm 3,61^{\mathrm{c}}$ & $13,0 \pm 1,30^{\mathrm{c}}$ & $3 \pm 0,0^{\mathrm{a}}$ & $17,3 \pm 2,5^{\mathrm{c}}$ & $4,33 \pm 0,21^{\mathrm{c}}$ \\
\hline
\end{tabular}

Keterangan: angka yang diikuti huruf yang berbeda pada kolom yang sama menunjukkan adanya perbedaan yang nyata ( $p>0,05$ ); $S A G=$ suhu awal gelatinisasi; PV = peak viscosity (viskositas puncak); TV = trough viscosity (viskositas pasta panas); BV = breakdown viscosity; $\mathrm{FV}=$ final viscosity (viskositas akhir); $\mathrm{SV}=$ setback viscosity; $\mathrm{tt}=$ tidak terdeteksi

mengalami proses modifikasi. Modifikasi dengan pregelSE menunjukkan kadar abu lebih rendah 1,2 kali dibandingkan dengan perlakuan pregel-pH3-SE dan pregel-pH4-SE (Tabel 1). Peningkatan kadar abu pada pregel-pH3-SE dan pregel-pH4-SE disebabkan oleh residu asam sitrat. Peningkatan kadar abu juga terjadi pada hidrolisis pati, antara lain pati garut menggunakan $\mathrm{HCl}$ (Faridah et al., 2013). Kadar abu dari hidrolisat pati garut menggunakan katalis $\mathrm{HCl}$ meningkat menjadi 3,69\% dibandingkan pati alaminya yaitu $0,22 \%$. Peningkatan kadar abu pada pati hidrolisis secara asam disebabkan residu mineral dari proses netralisasi asam dengan $\mathrm{NaOH}$.

\section{Analisis Kelarutan}

Kelarutan dekstrin pada perlakuan kombinasi menggunakan SE dan asam sitrat meningkat jika dibandingkan dengan tanpa penambahan asam sitrat (Tabel 1). Uji ANOVA pada tingkat signifikansi 5\% menunjukkan bahwa kombinasi perlakuan SE dan asam sitrat berpengaruh nyata terhadap kelarutan dekstrin. Modifikasi pregel-pH3-SE meningkatkan kelarutan dekstrin 1,2 kali dibandingkan dengan modifikasi pregelSE. Hal ini dapat disebabkan asam sitrat pada hidrolisis pati (pregel-pH3-SE dan pregel-pH4-SE) menyebabkan degradasi molekul pati lebih intensif sehingga menghasilkan molekul yang lebih kecil (Tabel 2). Hal ini juga terjadi pada hidrolisis pati jagung (Sun et al., 2013) dan pati ubi jalar (Babu et al., 2015). Kelarutan hidrolisat pati ubi jalar meningkat $85 \%$ setelah diperlakukan dengan asam sitrat pada $\mathrm{pH} \leq 4$.

\section{Analisis Dextrose Equivalent}

DE dapat digunakan sebagai ukuran terhadap jumlah pati yang telah dihidrolisis. DE semakin meningkat dengan peningkatan jumlah pati yang terhidrolisis. Hal ini terjadi karena reaksi hidrolisis memotong ikatan polimer pati sehingga diperoleh oligomer dengan rantai yang lebih pendek dan menghasilkan gula reduksi dari hasil pemotongan tersebut. Tabel 2 menunjukkan bahwa DE meningkat pada perlakuan kombinasi SE dan asam sitrat dibandingkan dengan SE tanpa penambahan asam sitrat. DE pregel-AS-pH4 dan pregel-AS-pH3 meningkat sekitar 1,3 kali dan 1,4 dibandingkan dengan pregel-AS. Hal ini menunjukkan bahwa kadar asam sitrat berpengaruh signifikan terhadap hidrolisis pati. Asam sitrat merupakan katalisator pada hidrolisis pati (Olsson et al., 2013; Babu et al., 2015). Semakin tinggi konsentrasi asam yang ditambahkan $(\mathrm{pH} 4$ menjadi $\mathrm{pH} 3)$ maka DE yang diperoleh meningkat. Hal ini juga terjadi pada pati ubi jalar (Babu et al., 2015). Peningkatan konsentrasi asam sitrat dari 1 ke $5 \%$ dapat meningkatkan nilai DE masing-masing sebesar 1,2 kali atau DE dari 1,9 ke 2,34. Namun perlakuan asam sitrat saja menghasilkan nilai DE lebih rendah dibandingkan dengan pregel-pH4-SE (Tabel 2). Jadi perlakuan kombinasi steam explosion dan asam sitrat meningkatkan hidrolisis pati.

Selain itu, nilai $D E$ berpengaruh terhadap sifat dari dekstrin. DE yang terlalu rendah dapat menyebabkan produk mudah mengalami retrogradasi, sedangkan $D E$ yang terlalu tinggi akan menghasilkan produk berupa glukosa dengan higroskopisitas yang tinggi (Prasetyo et al., 2018). Dektrin yang mempunyai nilai DE pada kisaran 3-20 baik digunakan dalam proses kemasan dan enkapsulasi karena sesuai dengan karakteristik mutu dekstrin (Souza et al., 2018), sehingga dekstrin pregelAS, pregel-pH3-SE dan pregel-pH4-SE memenuhi kriteria dekstrin untuk keperluan tersebut. 


\section{Rata-rata Berat molekul}

Proses hidrolisis merusak granula pati dan memecah rantai pati menjadi lebih pendek. Tabel 2 menunjukkan bahwa berat molekul dekstrin turun setelah adanya kombinasi perlakuan dengan asam sitrat. Hal ini menunjukkan semakin banyak polisakarida yang terdegradasi menjadi mono-, di-sakarida dan oligosakarida setelah kombinasi perlakuan. Berat molekul terendah di peroleh pada perlakuan kombinasi pregelpH3-SE dikuti oleh pregel-pH4-SE, masing-masing mengalami penurunan sebesar 1,5 dan 1,2 kali dibandingkan dengan pregel-SE (Tabel 2). Hal ini disebabkan asam pada proses hidrolisis dapat menyerang daerah amorf maupun kristalin dari granula pati dan memotong ikatan molekul pati (Omojola et al., 2010). Rantai pati yang lebih pendek memiliki berat molekul yang lebih kecil sehingga meningkatkan daya larut (Tabel 1). Hasil yang sama dilaporkan pada hidrolisis pati ubi jalar menggunakan asam sitrat (Olsson et al., 2013). Berat molekul hidrolisat menurun signifikan pada $\mathrm{pH} \leq 4$, namun degradasi pati tidak terjadi pada $\mathrm{pH}$ $\geq 4$. Menzel et al., (2013) juga melaporkan bahwa ubi jalar yang dihidrolisis dengan asam sitrat (5 pph) menghasilkan hidolisat dengan berat molekul $3,4 \times 10^{6}$ $\mathrm{g} / \mathrm{mol}$, sedangkan pada konsentrasinya $30 \mathrm{pph}$ berat molekul turun menjadi $0,2 \times 10^{6} \mathrm{~g} / \mathrm{mol}$.

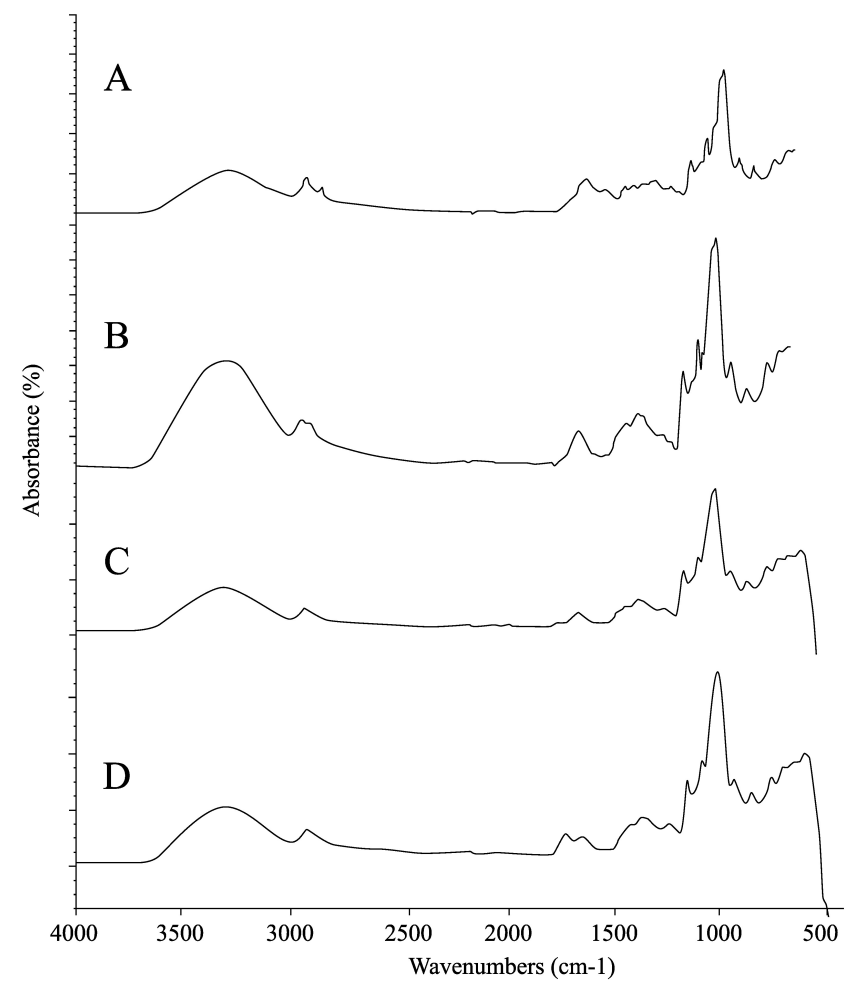

Gambar 1. Profil FTIR pati Alami (A), modifikasi pati batang kelapa sawit kombinasi pregelatinisasi-steam explotion (pregel-SE), pregelatinisasi, asam sitrat $\mathrm{pH} 4$ dan steam explotion (pregel-pH4-SE) dan pregelatinisasi, asam sitrat $\mathrm{pH}$ 3 dan steam explotion (pregel-pH3-SE).

\section{Analisis FTIR}

Perubahan kimia pati batang kelapa sawit termodifikasi (dekstrin) dapat dianalisa dengan FT-IR. Perubahan kimiawi dapat diidentifikasi melalui perubahan gugus fungsional dari dekstrin. Gambar 1 memperlihatkan spektrum FTIR dari pati alami dan dektrin dari perlakuan kombinasi pregelatinisasi, hidrolisis asam dan SE. Secara umum absorpsi pada bilangan gelombang $800-1200 \mathrm{~cm}^{-1}$ menunjukkan gugus dari getaran peregangan cincin anhidroglukosa (Sritham et al., 2017). Gugus $\mathrm{C}=\mathrm{O}$ dari gugus asam karboksilat ditunjukkan dengan absorpsi di wilayah bilangan gelombang antara 1690 dan $1745 \mathrm{~cm}^{-1}$. Absorpsi pada bilangan gelombang antara 2800 dan $3000 \mathrm{~cm}^{-1}$ merupakan ciri dari gugus deformasi $\mathrm{C}-\mathrm{H}$; dan absorpsi pada bilangan gelombang antara 3000 dan $3600 \mathrm{~cm}^{-1}$ merupakan gugus $\mathrm{OH}$ stretching. Absorpsi ditandai dengan adanya pita vibrasi (peak).

Pati alami mempunyai pita vibrasi lebih rapat (kompleks) pada bilangan gelombang $800-1200 \mathrm{~cm}^{-1}$ dibandingkan dengan dekstrin. Pita-pita vibrasi pada wilayah bilangan gelombang ini merupakan ciri khas (finger print) dari pati batang kelapa sawit. Absorpsi di wilayah bilangan gelombang antara 1690 dan $1745 \mathrm{~cm}^{-1}$ menunjukkan adanya gugus $\mathrm{C}=\mathrm{O}$ dari gugus asam karboksilat. Pregel-SE dan pregel-pH4-SE memiliki bilangan gelombang yang hampir sama, yaitu 1636 dan $1638 \mathrm{~cm}^{-1}$. Namun pada pregel-pH3-SE absorpsi tersebut bergeser menjadi bilangan gelombang 1717 $\mathrm{cm}^{-1}$. Munculnya pita vibrasi di wilayah $1717 \mathrm{~cm}^{-1}$ pada perlakuan pregel-pH3-SE diikuti dengan pelebaran luas area di wilayah $\mathrm{OH}$ streching pada bilangan gelombang $3303 \mathrm{~cm}^{-1}$ menunjukkan adanya interaksi antara dekstrin dan asam sitrat. Hasil ini sesuai dengan penelitian Castro-Cobado et al. (2015). Kombinasi maltodekstrin dan asam sitrat menunjukkan adanya absorpsi pada bilangan gelombang $1713 \mathrm{~cm}^{-1}$ disertai perluasan luas puncak $\mathrm{OH}$ pada absorbsi di bilangan gelombang 3334 $\mathrm{cm}^{-1}$.

Jika dibandingkan dengan pati alami maka pita vibrasi pada perlakuan pregel-SE, pregel-pH3-SE dan pregel-pH4-SE mengalami perubahan dan pergeseran seiring dengan perubahan gugus fungsional yang disebabkan terjadinya hidrolisis ikatan pada rantai molekul pati. Hasil menunjukkan bahwa beberapa pita vibrasi tidak terdeteksi pada pregel-SE jika dibandingkan dengan pati alami (bilangan gelombang 702, 1242, 1412 $\left.1415,1547,2850 \mathrm{~cm}^{-1}\right)$. sedangkan pada pregel-pH4SE, pita vibrasi yang tidak terdeteksi menjadi bertambah (bilangan gelombang 758, 928, $1077 \mathrm{~cm}^{-1}$ ). Pita vibrasi pada bilangan gelombang 854, 928 dan $1077 \mathrm{~cm}^{-1}$ tidak terdeteksi pada kombinasi pregel-pH3-SE. Penurunan jumlah pita-pita vibrasi yang terdeteksi dari dekstrin atau hilangnya beberapa pita vibrasi pada dekstrin mengindikasikan bahwa ikatan glikosidik molekul pati terhidrolisis lebih intensif dengan peningkatan konsentrasi asam sitrat atau penurunan $\mathrm{pH}$ SE $(\mathrm{pH}$ pregel-pH3-SE $<\mathrm{pH}$ pregel-pH4-SE $<\mathrm{pH}$ pregel- SE). $\mathrm{Hal}$ ini sesuai dengan penurunan berat molekul dekstrin dan kenaikan DE (Tabel 2).

\section{Profil Sifat Pasting}

Suhu awal gelatinisasi (SAG) adalah suhu pada saat mulai terjadi kenaikan viskositas suspensi pati bila dipanaskan. Pati batang kelapa sawit pada kombinasi 
perlakuan pregel-SE, pregel-pH3-SE dan pregel-pH4SE tidak menunjukkan adanya suhu gelatinisasi (Table 3). Hal ini dikarenakan pati telah mengalami gelatinisasi pada proses pregelatinisasi saat proses modifikasi pati.

Selain itu, peak viscosity atau viskositas puncak pregel-pH4-SE dan pregel-pH3-SE mengalami penurunan sebesar 2,4 dan 2,9 kali dibandingkan dengan Pregel-SE (Tabel 3). Hal ini disebabkan pati telah mengalami pregelatinisasi dan molekul pati telah terhidrolisis sehingga molekul pati lebih pendek dan berat molekulnya lebih kecil (Tabel 2). Selain itu, hidrolisis asam mengakibatkan terputusnya rantai ikatan pati pada wilayah amorf sehingga berat molekul menjadi menurun (Babu et al., 2015)

Trough viscosity (TV) atau viskositas pasta panas adalah viskositas pasta selama suhu dipertahankan pada $95^{\circ} \mathrm{C}$. TV pregel-SE, 3,1 kali lebih tinggi dibanding pregel-pH4-SE dan pregel-pH3-SE (16,3-13,0 cP) (Tabel 3). Semakin tinggi konsentrasi asam maka nilai TV semakin menurun dan mengakibatkan dekstrin semakin stabil terhadap pemanasan. Hasil ini hampir sama dengan penelitian Zang et al. (2019) dimana pati pea yang dihidrolisis menggunakan asam dapat menurunkan nilai TV. Peningkatan lama hidrolisis mengakibatkan TV semakin menurun.

Breakdown viscosity (BV) atau penurunan viskositas selama pemanasan menunjukkan kestabilan viskositas pasta selama pemanasan. TV dan nilai BD menunjukkan tren penurunan yang sama. BV pregel-SE tidak berbeda signifikan dengan pregel-pH4-SE dan Pregel-pH3-SE. Saat pemanasan hingga suhu $95^{\circ} \mathrm{C}$, amilosa pada pati terdispersi di dalam air semakin banyak dan terjadi pemutusan ikatan pada molekul pati sehingga terjadi perubahan viskositas yang besar dari viskositas puncak hingga viskositas panas (Babu et al., 2015).

Final viscosity (FV) atau viskositas akhir merupakan nilai viskositas pasta pati setelah tahap pendinginan (akhir holding $50^{\circ} \mathrm{C}$ ). Nilai $\mathrm{FV}$ pada perlakuan pregel-SE adalah 3,4 dan 4,6 kali lebih tinggi dibandingkan dengan pregel-pH4-SE dan pregel-pH3SE (Tabel 3). Hal ini disebabkan asam sitrat menghidrolisis pati sehingga viskositas akhir sampel turun. Peningkatan konsentrasi asam akan meningkatkan hidrolisis pati sehingga nilai viskositas semakin menurun yang disebabkan oleh terbentuknya rantai lebih pendek (Sandhu et al., 2007). Hasil ini sesuai dengan penelitian Babu et al. (2015) bahwa hidrolisis asam mengakibatkan terputusnya ikatan glikosidik amilopektin sehingga menurunkan viskositas.

Setback viscosity menunjukkan nilai kenaikan viskositas ketika pasta didinginkan yang diperoleh dengan menghitung selisih antara viscositas pasta dingin dengan viskositas pasta saat mulai pendinginan (pasca pemanasan). Modifikasi pati berpengaruh signifikan terhadap nilai SV. Pregel-SE memiliki nilai setback 4,2 kali dan 6,85 kali lebih tinggi dibandingkan dengan pregel-pH4-SE dan pregel-pH3-SE (Tabel 3). Hal ini sesuai dengan Polnaya et al. (2018). Nilai SV pati sagu Ihur yang dimodifikasi dengan asam menghasilkan SV (304 - $470 \mathrm{cp})$ lebih rendah dibandingkan dengan pati alaminya (1291 cp). Peningkatan konsentrasi $\mathrm{HCl}$ menyebabkan SV semakin rendah. Semakin tinggi nilai setback menunjukkan semakin tinggi pula kecenderungan untuk membentuk gel (meningkatkan viskositas) selama pendinginan. Kombinasi pregel-SE dengan penambahan asam berpengaruh nyata terhadap penurunan viskositas setback. Hal ini disebabkan oleh pembentukan rantai pendek amilosa dan degradasi molekul pati yang lebih intens terhadap cabang amilopektin (Astuti et al., 2018).

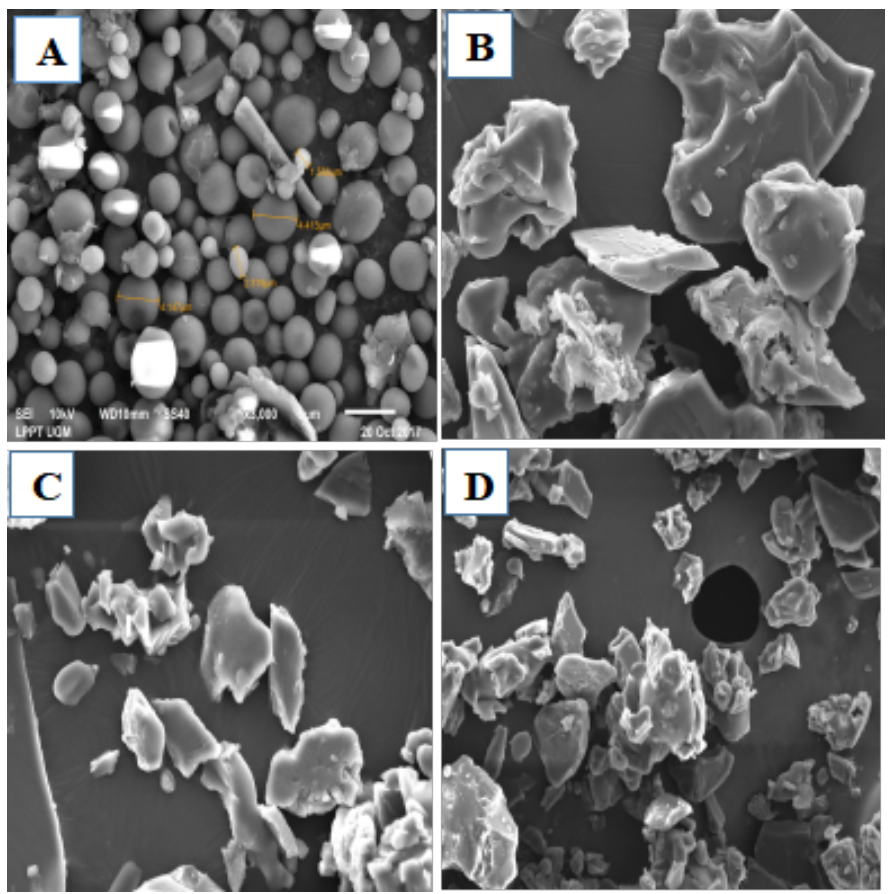

Gambar 2. Makroskopik pati alami (A), dan perlakuan kombinasi modifikasi pati batang kelapa sawit dengan metode pregelatinisasi dan steam explosion (B), pregelatinisasi, asam sitrat $\mathrm{pH} 4$ dan steam explosion (C), dan pregelatinisasi,

asam sitrat $\mathrm{pH} 3$ dan steam explosion (D) dengan perbesaran $1000 \mathrm{X}$

\section{Analisis Scaning Electron Microscopy}

Gambar 2 menunjukkan bahwa granula pati pregel-SE, pregel-pH3-SE dan pregel-pH4-SE mengalami perubahan bentuk tidak beraturan. Gambar 2A menunjukkan bahwa pati alami memiliki bentuk yang bulat dan permukaan yang halus. Hasil ini sesuai dengan penelitian Ridwansyah (2010), bahwa granula pati batang kelapa sawit berbentuk bulat. Proses modifikasi pati dengan kombinasi pregelatinisasi dan steam explosion mampu merusak granula pati dan struktur molekulnya sehingga terlihat granula pecah dan tidak beraturan (Gambar 2B). Hal ini terjadi juga pada pati sagu (Reeve, 1992). Bentuk granula pati sagu pecah akibat proses gelatinisasi. Namun perlakuan pregelpH4-SE dan pregel-pH3-SE memberikan ukuran yang lebih kecil dan seragam dibandingkan dengan pregel-SE. Hidrolisis asam dapat menyerang granula pati pada dua tahap yaitu penyerangan secara cepat pada bagian amorf dan tahap penyerangan yang lebih lambat pada bagian kristalin pada fraksi amilopektin (Wurzburg, 1989). Gambar 2D menunjukkan bahwa konsentrasi asam yang lebih tinggi mengakibatkan permukaan granula menjadi lebih rusak dan ukuran granula yang 
semakin kecil. Berbeda dengan penelitian Babu et al. (2015) terhadap pati ubi jalar. Granula pati tidak semuanya pecah pada konsentrasi asam sitrat rendah. Peningkatan konsentrasi asam sitrat mengakibatkan peningkatan kerusakan granula pati. Namun, granula pati masih terlihat pada konsentrasi asam sitrat $5 \%$. Hal ini menunjukkan bahwa kombinasi steam explotion dan asam sitrat menghasilkan kerusakan granula tinggi akibat molekul pati terhidrolisis.

\section{Kesimpulan}

Modifikasi pati menggunakan kombinasi steam explosion dengan pregelatinisasi dan asam sitrat pada $\mathrm{pH} 3$ dan $\mathrm{pH} 4$ berhasil meningkatkan degradasi pati lebih besar dan efektif memperbaiki struktur molekul dan sifat fisikokimia pati batang kelapa sawit. Secara umum, kombinasi pregelatinisasi, SE dan asam meningkatkan kelarutan dan menurunkan berat molekul. Semakin tinggi konsentrasi asam semakin besar degradasi pati. Kombinasi modifikasi terbaik diperoleh pada perlakuan pregel-pH3-SE. Metode ini berhasil dilakukan dengan meningkatkan kelarutan $75,94 \%$, penurunan berat molekul $60100 \mathrm{~g} / \mathrm{mol}$ dan penurunan viskositas yang ditandai tidak terdeteksinya sifat pasting setelah dimodifikasi. Peningkatan nilai DE yang merupakan syarat mutu produk dekstrin paling tinggi diperoleh pada perlakuan pregel-pH3-SE yaitu 15,92 $\pm 0,68$. Penelitian ini menunjukkan bahwa modifikasi pati menggunakan kombinasi steam explosion dengan pregelatinisasi dan asam sitrat pada $\mathrm{pH} 3$ dan $\mathrm{pH} 4$ dapat meningkatkan degradasi pati dan efektif memperbaiki sifat fisikokimia dekstrin pati batang kelapa sawit.

\section{Ucapan Terimakasih}

Penelitian ini di biayai oleh Kementerian Riset, Teknologi, dan Pendidikan Tinggi, Republik Indonesia, yang dikelola oleh Universitas Gadjah Mada melalui skema Penelitian Disertasi Dokter (PDD) Tahun 2019.

\section{Daftar Pustaka}

Adapa, P., Tabil, L., Schoenau, G. 2010. Physical and frictional properties of non-treated and steam exploded barley, canola, oat and wheat straw grinds. Powder Technology 201:230-241. DOI: 10.1016/j.powtec.2010.03.038.

Aktas-Akyildiz, E., Mattila, O., Sozer, N., Poutanen, K., Koksel, H., Nordlund, E. 2017. Effect of steam explosion on enzymatic hydrolysis and baking quality of wheat bran. Journal of Cereal Science 78: 25-32. DOI: 10.1016/j.jcs.2017.06.011

AOAC. 1971. Official methods of analysis of the association of official analytical chemists. Journal of Pharmaceutical Sciences 60(2):334. DOI: 10.1002/jps.2600600253

Astuti, R.M., Asiah, N., Setyowati, A., Fitriawati, R. 2018. Effect of physical modification on granule morphology, pasting behavior, and functional properties of arrowroot (Marantha arundinacea $\mathrm{L}$ ) starch. Food Hydrocolloids 4288:1-26. DOI: 10.1016/j.foodhyd.2018.02.029

Avaltroni, F., Bouquerand, P. E., Normand, V. 2004.
Maltodextrin molecular weight distribution influence on the glass transition temperature and viscosity in aqueous solutions. Carbohydrate Polymers 58:323-334. DOI: 10.1016/ j.carbpol.2004.08.001.

Azemi, M., Noor, M. 1999. Physico-chemical properties of oil palm trunk starch. Starch/Stärke 51 (108): 293-301. DOI: 10.1002/star.199909512.

Babu, A.S., Parimalavallia, R., Rudra, S.G. 2015. Effect of citric acid concentration and hydrolysis time on physicochemical properties of sweet potato starches. International Journal of Biological Macromolecules 80:557-565. DOI: 10.1016/j.ijbiomac.2015.07.020.

Bi, Y., Zhang, Y., Jiang, H., Hong, Y., Gu, Z., Cheng, L., Li, Z., Li, C. 2017 Molecular structure and digestibility of banana flour and starch. Food Hydrocolloids 72:219-227. DOI: 10.1016/ j.foodhyd.2017.06.003.

Blazek, J., Gilbert, E.P. 2010. Effect of enzymatic hydrolysis on native starch granule structure. Biomacromolecules 11:3275-3289. DOI: 10.1021/bm101124t.

Cahyaningtyas, A.A., Ermawati, R., Supeni, G., Syamani, F. A., Masruchin, N., Kusumaningrum, W. B. 2019. Modifikasi dan karakterisasi pati batang kelapa sawit secara hidrolisis sebagai bahan baku bioplastik. Jurnal Kimia dan Kemasan 41(1):37-44. DOI: $10.24817 /$ jkk.v41i1.4623.

Castro-Cabado, M., Parra-ruiz, F. J., Casado, A. L., Román, J. S. 2015. Thermal crosslinking of maltodextrin and citric acid. Methodology to control the polycondensation reaction under processing conditions. Polymers \& Polymer Composites 24(8):643-654. DOI: $10.1177 / 096739111602400803$.

Dastidara, T. G., Netravali, A. N. 2012. Green crosslinking of native starches with malonic acid and their properties. Carbohydrate Polymers 90(4): 1620-1628. DOI: 10.1016/j.carbpol.2012.07.041.

Dutta, H., Paul, S. K., Kalita, D., Mahanta, C. L. 2011. Effect of acid concentration and treatment time on acid-alcohol modified jackfruit seed starch properties. Food Chemistry 128 (2):284-291. DOI: 10.1016/j.foodchem.2011.03.016

Faridah, D. N., Rahayu, W., Apriyadi, M. S. 2013. Modification of arrowroot (Marantha arundinacea L.) starch through acid hydrolysis and autoclavingcooling cycling treatment to produce resistant starch type. Jurnal Teknologi Industri Pertanian 23(1): 61-69.

Ferrinia, L. M. K., Rochaa, T. S., Demiateb, I. M., Francoa, C. M. L. 2008. Effect of acid-methanol treatment on the physicochemical and structural characteristics of cassava and maize starches. Starch/Stärke 60:417-425. DOI: 10.1002/ star.200700712.

Jacquet, N., Vanderghem, C., Danthine, S., Quiévy, N., Blecker, C., Devaux, J., Paquot, M. 2012. Influence of steam explosion on physicochemical properties and hydrolysis rate of pure cellulose 
fiber. Bioresource Technology 121: 221-227. DOI: 10.1016/j.biortech.2012.06.073.

Gbenga, B. L., Olakunle, O., Adedayo, A. M. 2014. Influence of pregelatinization on the physicochemical and compressional characteristics of starches obtained from two local varieties of Dioscorea rotundata. International Organization of Scientific Research Journal of Pharmacy 4(6):24-32.

Khan, A ., Rahman, U. U., Siddiqui, S., Irfan, M., Shah, A. A., Badshah, M., Hasan, F., Khan, S. 2019. Preparation and characterization of resistant starch type III from enzymatically hydrolyzed maize flour 46:4565-4580. Molecular Biology Reports. DOI: 10.1007/s11033-019-04913-5.

Khanna, S., Tester, R. F. 2006. Influence of purified konjac glucomannan on the gelatinisation and retrogradation properties of maize and potato starches. Food Hydrocolloids 20:567-576. DOI: 10.1016/j.foodhyd.2005.05.004.

Liu, Q. 2002. A Study of enzymatic hydrolysis of starch in potato pulp. Journal of Food Science 67 (6): 2113-2117. DOI: 10.1111/j.1365-2621. 2002.tb09510.x.

Majumdar, S., Bhattacharyya, D. K., Bhowal, J. 2015. Study on enzymatic hydrolysis of sal (Shorearobusta) starch to dextrin. Annals of Biological Research 6(6):8-12.

Mei, J., Zhou, D., Jin, Z., Xu, X., Chen, H. 2015. Effects of citric acid esterification on digestibility, structural and physicochemical properties of cassava starch. Food Chemistry 187:378-384. DOI: 10.1016/j.foodchem.2015.04.076.

Menzel, C., Olsson, E., Plivelic, T. S., Andersson, R., Johansson, C., Kuktaite, R., Järnströmb, L., Koch, K. 2013. Molecular structure of citric acid crosslinked starch films. Carbohydrate Polymers 96(1):270-276. DOI: 10.1016/j.carbpol. 2013.03.044.

Miller, G.L., 1959. Use of dinitro salicylic acid reagent for determination of reducing sugar. Analysis Chemistry 31:426-428. DOI: 10.1021/ ac60147a030.

More, P. R., Talib, M. I., \& Parate, V. R. 2017. Development of modified instant starch from taro (Colocasia esculenta) by gelatinization. Journal of Environmental Science, Toxicology and Food Technology 11(1): 52-59. DOI: 10.9790/24021101025259.

Munegumi, T., Inutsuka, M., Hayafuji, Y. 2016. Investigating the hydrolysis of starch using a-Amylase contained in dishwashing detergent and human saliva. Journal of Chemical Education 93(8):1401-1405. DOI: 10.1021/acs.jchemed. $5 \mathrm{~b} 00545$.

Olivato, J.B., Grossmann, M.V.E., Bilck, A.P., Yamashita, F. 2012. Effect of organic acids as additives on the performance of thermoplastic starch / polyester blown films. Carbohydrate Polymers 90(1):159164. DOI: 10.1016/j.carbpol.2012.05.009.

Olsson, E., Menzel, C., Johansson, C., Andersson, R.,
Koch, K., Järnström, L. 2013. The effect of pH on hydrolysis, cross-linking and barrier properties of starch barriers containing citric acid. Carbohydrate Polymers 98(2):1505-1513. DOI: 10.1016/ j.carbpol.2013.07.040.

Omojola, M., Akinkunmi, Y., Olufunsho, K., Egharevba, H., Martins, E. 2010. Isolation and Physicochemical characterization of Cola starch. African Journal of Food Agriculture Nutrition and Development 10(7):2884-2900. DOI: 10.4314/ajfand.v10i7.59042.

Permanasari, A.R., Yulistiani, F. 2017. Liquid sugar production from red sorghum starch as raw material to produce high fructose syrup (HFS). Advanced Science Letters 23(6): 5775-5779. DOI:10.1166/asl.2017.8829.

Polnaya, F. J., Huwae, A. A., Tetelepta, G. 2018. Karakteristik sifat fisiko-kimia dan fungsional pati sagu ihur (Metroxylon sylvestre) dimodifikasi dengan hidrolisis asam physico-chemical. Agritech 38(1):7-15. DOI: 10.22146/ agritech.16611.

Prasetyo, B. E., Annisa, P., Yuliasmi, S. 2018. Karakterisasi dekstrin dari pati kacang merah (Vigna angularis (Wild) Ohwi and Ohashi) dengan metode enzimatis. Conference Series Tropical Medicine 1(3):20-24. DOI: 10.32734/tm.v1i3.255.

Rahmawati, A.Y., Sutrisno, A. 2015. Enzymatic hydrolysis of purple sweet potato (Ipomea batatas L.) flour into functional glucose syrup: Annual Review Jurnal Pangan dan Agroindustri 3 (3):1152-1159.

Reeve, A. 1992. Starch hydrolysis: processes and equipment. In F.W. Schenck, R.E. Hebeda (Eds.), Starch hydrolysis products: worldwide technology, production, and applications (pp. 79-120). New York: VCH Publishers

Ridwansyah M., Nasution, Z., Sunarti, T.C. dan , Fauzi, A.M. 2010. Karakteristik sifat fisiko-kimia pati kelapa sawit. Jurnal Teknik Industri Pertanian 17(1):1-6.

Sarifudin, A., Assiry, A. M. 2013. Some physicochemical properties of dextrin produced by extrusion process. Journal of the Saudi Society of Agricultural Sciences 13:100-106. DOI: 10.1016/j.jssas.2013.02.001.

Sandhu, K.S., Singh, N., Lim, S.T. 2007. A comparison of native and acid thinned normal and waxy corn starches; physicochemical, thermal, morphological and pasting properties. Food Science and Technology 40(9):1527-1536. DOI: 10.1016/j.Iwt.2006.12.012.

Shang,Y., Chao, C., Yu, J., Copeland, L., Wang, S., Wang, S. 2018. Starch spherulites prepared by a combination of enzymatic and acid hydrolysis of normal corn starch. Journal of Agricultural and Food Chemistry 66(25):1-33. DOI: 10.1021/acs.jafc.8b01370.

Souza, I.N., Soares, C.M.F., Souza, R.L., Freire, M.G., Silva, A. 2018. Fluid Phase Equilibria Aqueous two-phase systems formed by maltodextrin and 
acetonitrile: Phase diagrams and partitioning studies. Fluid Phase Equilibria 476:179-185. DOI: 10.1016/j.fluid.2018.08.005.

Sritham, E., Gunasekaran, S. 2017. FTIR spectroscopic evaluation of sucrose-maltodextrin-sodium citrate bioglass. Food Hydrocolloids 70:371-382. DOI: 10.1016/j.foodhyd.2017.04.023.

Sui, W., Xie, X., Liu, R., Wu, T., Zhang, M. 2018. Effect of wheat bran modification by steam explosion on structural characteristics and rheological properties of wheat flour dough. Food Hydrocolloids 84: 571-580. DOI: 10.1016/j.foodhyd.2018.06.027.

Sun, Q., Zhu, X., Si, F., Xiong, L. 2013. Effect of acid hydrolysis combined with heat moisture treatment on structure and physicochemical properties of corn starch. Journal Food Science Technology 52 (1):375-382. DOI: 10.1007/s13197-013-0998-7.

Triyono, A., Andriansyah, R. C. E., Luthfiyanti, R., Rahman, T. 2017. Development of modified starch technology (maltodextrin) from commercial tapioca on semi production scale using oil heater dextrinator. Conferance Series: Earth and Environmental Science 101:1-8. DOI: 10.1088/1755-1315/101/1/012026.

Trung, P. T. B., Ngoc, L. B. B., Hoa, P. N., Tien, N. N. T., Hung, P. V. 2017. Impact of heat-moisture and annealing treatments on physicochemical properties and digestibility of starches from different colored sweet potato varieties. International Journal of Biological Macromolecule 105(Pt1):1071-1078. DOI: 10.1016/j.jjbiomac. 2017.07.131.

Utrilla-Coelloa, R.G., Hernández-Jaimesa, C., CarrilloNavasa, H., Gonzáleza, F., Rodrígueza, E., BelloPérez, L. A., Vernon-Cartera, E. J., AlvarezRamireza, J. 2004. Acid hydrolysis of native corn starch: Morphology, crystallinity, rheological and thermal properties. Carbohydrate Polymers 103: 596-602. DOI: 10.1016/j.carbpol.2014.01.046.
Waliszewskia, K.N., Aparicioa, M.A., Bello, L.A., Monroya, J.A. 2003. Changes of banana starch by chemical and physical modification. Carbohydrate Polymer 52:237-242. DOI: 10.1016/S01448617(02)00270-9

Wang, K., Chen, J., Sun, S., Sun, R. 2015. Steam Explosion 6: 75-104. DOI: 10.1016/B978-0-12800080-9.00006-2.

Wanderley, M.C.D.A., Martín, C., Rocha, G.J.D.M., Gouveia, E.R. 2013. Increase in ethanol production from sugarcane bagasse based on combined pretreatments and fed-batch enzymatic hydrolysis. Bioresource Technology 128:448-453. DOI:10.1016/j.biortech.2012.10.131.

Wojtasz-mucha, J., Hasani, M., Theliander, H. 2017. Hydrothermal pretreatment of wood by mild steam explosion and hot water extraction. Bioresource Technology. DOI:10.1016/j.biortech.2017.05.061.

Wong, C.W., Muhammad, S.K.S., Dzulkiflfly, M.H., Saari, N., Ghazali, H.M. 2007. Enzymatic production of linear long-chain dextrin from sago (Metroxylon sagu) starch. Food Chemistry 100(2):774-780. DOI: 10.1016/j.foodchem.2005.10.040

Wurzburg, O.B. 1989. Modified starches: Properties and uses, CRC Press, Boca Raton, Florida.

Zhang, H., Hou, H., Liu, P., Wang, W., Dong, H. 2019. Effects of acid hydrolysis on the physicochemical properties of pea starch and its film forming capacity. Food Hydrocolloids 87:173-179. DOI: 10.1016/j.foodhyd.2018.08.009. 